\title{
Managing risks in work-integrated learning programmes: A cross-institutional collaboration
}

\begin{abstract}
Purpose - Work-integrated learning (WIL) poses legal, reputation, operational, strategic and financial risks for higher education providers (HEPs). The purpose of this paper is to explore how HEPs can manage five significant WIL risks involving intellectual property, student disability and medical conditions, the host organisation, and the legal literacy of WIL practitioners.
\end{abstract}

Design/Methodology/Approach - This paper is a cross-institutional collaboration of WIL practitioners who explored risk management in WIL programmes. The case study is presented as a cross-case analysis to assist WIL stakeholders with evaluating their risk management frameworks. A description about the significance of the risk (in terms of causes and consequences), as well as practices to manage the risk, is presented under each of the five WIL risks.

Findings - WIL practitioners described a series of risk management practices in response to five significant risks in WIL programmes. Four themes underpinning these risk management practices-balance, collaboration, relationship management, and resources - are conceptualised as characteristics that can serve as guiding principles for WIL stakeholders in risk management.

Practical Implications - The findings can be applied by WIL stakeholders to evaluate and improve existing risk management frameworks, and to improve their legal literacy in relation to WIL. The study also demonstrates the capacity for collaborative research to address practice issues in WIL.

Originality/Value - This is the first known study which employs a cross-institutional collaboration of WIL practitioners to contribute towards the body of knowledge examining risk management in WIL programmes.

Keywords - risk management, risk, work-integrated learning, collaboration 
Paper type - Case Study 


\section{Introduction}

This article explores how higher education providers (HEPs) can manage five significant risks that may undermine the delivery of work-integrated learning (WIL) programmes. WIL is an umbrella term used to describe a range of activities delivered by academic disciplines (e.g. placement, practicum, cooperative education, internship and work-based learning) which combine formal learning with student exposure to real or simulated workplace settings (Cameron, 2016). The benefits of WIL to its stakeholders-host organisations that accept students into the workplace, HEPs and students-is well documented (Freudenberg et al., 2010). HEPs have embraced WIL as a strategic opportunity to enhance their reputation to attract and retain students, engage the community and strengthen industry relationships. A positive institution-industry relationship may lead to future placements offered by the host organisation (WIL placements), as well as research partnerships and consultancies (Cooper et al., 2010; Patrick et al., 2008).

Less attention is paid in the literature to the risks that may impact the delivery of WIL programmes. There are numerous reported instances of conduct by WIL stakeholders before, during and after a WIL placement that have posed legal risks for the HEP (Cameron, 2016, Appendix A). In this article, risk is defined as an event or circumstance (collectively an 'issue') which positively or negatively affects WIL programmes. The definition of risk is drawn from the Enterprise Risk Management (ERM) literature. ERM conceptualises risk as opportunities (positive) and hazards (negative), and risk management involves managing the opportunities and minimising the hazards of a higher education activity (Ackley et al., 2007; Cassidy et al., 2001). Therefore, if the delivery of WIL programmes is an institutional goal, then any issue which affects WIL is a risk. In fact, there are a variety of issues which affect WIL including: compliance with rules and regulations (legal risk), the day to day operation of the WIL programme (operational risk), the HEP's ability to achieve its goals with respect to WIL programmes (strategic risk), the reputation of the HEP (reputation risk), and the loss of assets or financial resources of the HEP (financial risk) (Ackley et al., 2007; Cassidy et al., 2001). Risk management is the practices used to address these risks.

The study reported in this article is a cross-institutional collaboration of WIL practitioners, who examined how HEPs can manage five significant risks in WIL related 
to: intellectual property (IP), student disability and medical conditions; the host organisation; and the legal literacy of WIL practitioners. WIL practitioners are higher education employees involved with the management and/or delivery of WIL programmes. The article first reviews the literature supporting the need for collaborative research in WIL which explores important practice issues. Risk management is then identified as one such practice issue for HEPs. The literature review is followed by a description of the study design. The study is then presented as a series of practices that HEPs can employ to manage the five WIL risks, followed by a discussion which identifies four characteristics of risk management in WIL derived from the study findings. The article concludes with the authors' reflections on the collaborative process.

\section{Collaborative research in WIL}

The present study was motivated by two complementary research agendas in WIL: the development of cross-institutional collaboration; and a demand for research that transcends the positive aspects associated with WIL. Collaboration provides an environment for WIL practitioners to identify and explore issues that impact WIL, and to generate solutions that can improve WIL practice. Collaborative research involves disseminating the collaborative practice and its associated outcomes for the benefit of a wider WIL audience. Cross-institutional collaboration has produced orientation, education and practice resources for social work instructors (Berg-Weger et al., 2007), a vignette tool to improve the validity of host supervisor assessment of psychology students (Gonsalvez et al., 2013), as well as a formal network of WIL practitioners who developed a range of measures designed to improve education students' preparation for remote WIL placements (Trinidad et al., 2014). Collaborative research, with its focus on addressing practice issues, has the capacity to transcend studies which articulate the positive aspects of WIL. Both Zegwaard (2015) and Rowe (2015) have been critical of the scholarly emphasis on the benefits of WIL for stakeholders. WIL researchers should not ignore that "participating in WIL can also generate negative impacts" (Zegwaard, 2015, p. 90). Rowe (2015) argued that WIL researchers should pay more attention to negative results or neglected issues. Managing risk is one such practice issue in WIL, and more broadly a regulatory issue for HEPs. 


\section{Risk management in WIL}

WIL poses risks which, if not appropriately managed, may expose the institution to significant harm and undermine the delivery of WIL placements to students (Cameron, 2016). Developing and executing a robust risk management framework for WIL is not only a wise business strategy but may be a legal necessity. For instance, both Australia and the United Kingdom have recently implemented a risk-based approach to quality assurance in higher education (Higher Education Standards Framework (Threshold Standards) 2015 (Cth) ('HES Framework'); Higher Education and Research Act 2017 (UK), s 75). Under a risk-based approach, the level of regulatory scrutiny of institutions is based on the level of risk attributed to the activities of the institution. Institutions that have robust risk management frameworks should, in theory, encounter less regulatory burden or 'red tape' than 'high risk' institutions.

Risk management is also the legal responsibility of Australian institutions to maintain their HEP status. They must demonstrate that "risks to higher education operations have been identified and material risks are being managed and mitigated effectively" (HES Framework, section 6.2.1(e)). Further, WIL must be "quality assured, including assurance of the quality of supervision of student experiences" (HES Framework, section 5.4.1). According to the Tertiary Education Quality and Standards Agency (TEQSA), the national regulator of HEPs, the risks that may undermine quality in WIL include poor host and academic supervision, poor WIL programme design, the adverse impact of an unsuccessful WIL placement on the institution-host organisation relationship, and the failure to document the expectations and obligations of the parties in a written WIL agreement, such as the ownership of IP generated by the student on WIL placement (TEQSA, 2017). Quality assurance and risk management in WIL are symbiotic. Quality assurance requires the institution to manage risks that can impact the quality of WIL programmes.

\section{Study design}

The study is a cross-institutional collaboration of WIL practitioners who explore the topic of risk management in WIL. Research which involves the participants in the research process to address a practical problem within a specific setting - managing risks in WIL programmes - is an example of action research (Merriam, 2009). The primary goal of 
the cross-institutional collaboration was to present the findings in a way which can be used by WIL stakeholders to understand, evaluate and improve risk management at their own institutions.

The study has its origins at a workshop, during which the lead author presented ten risks in WIL frequently identified by university lawyers as part of his $\mathrm{PhD}$ thesis (Cameron, 2016). The lead author subsequently selected the five most frequently cited and/or discussed WIL risks in the workshop as the basis for the research project, which were:

1. The student assigns their intellectual property rights to the host organisation;

2. A student's disability or medical condition is not disclosed to the university and/or the host organisation;

3. Poor supervision of the student and/or poor attitude by the host organisation (“student as free labour")

4. A potential or current host organisation does not offer a WIL placement(s); and

5. WIL staff do not possess sufficient legal awareness of university policy, WIL programme design or provisions in a WIL agreement (legal literacy).

Five WIL practitioners at the workshop collaborated on the research project. Three WIL practitioners are professional (or non-academic) managers of staff responsible for the delivery of multiple WIL programmes, whereas the other two WIL practitioners are academic co-ordinators of one WIL programme in their discipline or faculty. Their experience as WIL practitioners range from one year to 12 years, and they operate within various academic disciplines (WIL disciplines) predominantly related to Business (Communication; Marketing; Hospitality; Management; Tourism; Events; Accounting, Finance, Economics, Property), but also Arts (Creative and Professional Writing, Media Arts), Law, Architecture and Health (Social Work). The small sample size would ordinarily be considered a research limitation, but this was attributable to the nature of the research-WIL practitioners are not just subjects, but active participants in the research.

Two research limitations relate to the scope and type of WIL programmes, the subject of this study. First, WIL practitioners generally discussed risk in the context of unpaid WIL programmes, which is more common in Australian HEPs than paid WIL programmes. The Australian higher education environment can be contrasted with countries such as 
Canada, in which a significant proportion of students complete paid co-operative education (or co-op) programs (Cameron et al., 2019), and the growth of degree and higher apprenticeships in the United Kingdom (Bravenboer and Lester, 2016). In these scenarios, the classification of the student as an employee will impact the risks encountered by the student, HEP and host organisation. For example, the student assignment of intellectual property (IP) rights to the host organisation may be a risk in unpaid WIL placements, but not if the student is employed by the host organisation based on the legal rule that an employer owns the IP created by employees in the course of their employment, unless the contract of employment provides otherwise (Copyright Act 1968 (Cth); s 35(6)). The second limitation is that the WIL activities which are the subject of this study do not extend to other work-based learning programmes (paid or unpaid), including higher and degree apprenticeships. A study of risk management related to higher apprenticeships and other paid WIL models could be the subject of future research. This research is pertinent as new WIL models emerge and existing WIL models evolve, which in an Australian context includes the potential broader use of higher apprenticeships (National Centre for Vocational Education Research, 2019).

There were six steps to the collaborative research process. First, the lead author issued WIL practitioners with a research project document. The document included instructions for completion, a list of definitions, and a questionnaire organised into three parts: demographic questions (Part 1), questions about each of the five WIL risks (Part 2) and general questions designed to gather additional information about management of the WIL risks (Part 3). The questions for each risk at Part 2 were:

1. How is this a risk to the university?

2. What do you do to manage this risk?

3. What assists you with managing this risk?

4. What are the challenges with managing this risk?

The lead author then reviewed and marked up each WIL practitioner response to the research project document with additional questions designed to clarify and/or expand their responses. During the third step, the lead author collated the responses to Parts 2 and 3 and published them in one Google Docs shared document for WIL practitioners to access and review. At step four, each WIL practitioner analysed the data by: 
1. Identifying and describing similar experiences they had with other WIL practitioners;

2. Providing additional information and examples which clarified or expanded their own responses;

3. Identifying and describing themes, relationships and key messages that emerged from the responses;

4. Providing general comments and insights that may deep understanding about risk management; and

5. Reflecting on the project, including best aspects of the collaboration and aspects that can be improved.

The lead author manually coded the data under the structural codes 'risk' and 'risk management' using holistic and descriptive techniques (Saldana, 2013), and then compared codes devised by two co-authors for validity. Four overarching themes underpinning risk management emerged from the key messages, relationships and themes identified by WIL practitioners-balance, collaboration, resources, and relationship management. The lead author then presented the study as a cross-case analysis, with the description about the risk and the risk management practices from each WIL practitioner (or case) disseminated under five headings, representing each of the five WIL risks (step five). The final step involved WIL practitioners evaluating the case study write up, which included making, reviewing and negotiating revisions to the manuscript.

\section{Findings}

\section{Student assignment of IP rights to the host organisation}

Students may assign, by way of a written agreement or deed, their rights to IP they generate on WIL placement to the host organisation. Unlike an employment relationship, the host organisation has no legal entitlement to IP generated by students on unpaid WIL placements. Nevertheless, the host organisation may have superior bargaining strength to the HEP and the student when negotiating IP. With a limited supply of WIL placements in a competitive higher education environment, there is a strategic risk that the host organisation withdraws the WIL placement if the student does not assign their IP rights. Students, who are focussed on securing a coveted WIL placement, may fail to appreciate the potential value of their work and the risk of giving up their IP. The HEP may not be, 
or seen to be, protecting students' rights if students do not understand the consequences of assignment.

HEPs can manage the risks associated with IP through: education of students and WIL practitioners, IP policies which make explicit that ownership of student IP remains with the student, and a standard WIL agreement template, prepared by the HEP, that binds the host organisation and HEP (bipartite) or the host, student and HEP (tripartite). Legal and administrative support can also assist WIL practitioners with risk management. For instance, an organisational restructure at one university has resulted in dedicated legal and WIL practitioners assigned to each faculty, and administrative staff being responsible for processing WIL agreements to ensure that WIL agreements are signed prior to the WIL placement.

The WIL agreement for unpaid placements will typically maintain the default position under IP policy that any IP created by the student during a placement remains the property of the student (developed IP). The exception provided in the WIL agreement is if the host organisation and student agree to a different arrangement. This raises a critical risk management issue: how should HEPs manage this alternative arrangement, if at all? One option is for HEPs to make clear in the WIL agreement that any exception to the rule is subject to a separate agreement between the host and the student. This attempt by the HEP at transferring risk means that WIL practitioners may nevertheless be unaware of the agreement (including any onerous provisions) entered by the student, who may be in an inferior bargaining position to the host.

Alternatively, HEPs can take greater responsibility for risk management by including one or more of the following IP provisions in the WIL agreement itself, preparing a separate deed signed by the student which addresses the issue of IP only, or a combination of both:

- The student owns the developed IP but grants the host organisation a nonexclusive, royalty-free, perpetual licence to use the IP for the host's business purposes.

- The host owns the developed IP but either:

○ The host grants the student a non-exclusive, royalty-free, perpetual licence to use the IP for the purposes of meeting WIL programme requirements (e.g. assessment); and/or 
- The student retains copyright in any reports, presentations or other materials created by the student for assessment purposes.

- The host owns the developed IP only.

WIL practitioners cannot properly identify and assess the risk with respect to any of these agreement types unless they have data about the WIL placement, particularly the scope, anticipated outcomes and the student's tasks and responsibilities. A centralised customer relationship management system $(\mathrm{CRM})$ for recording this data can facilitate risk management. The timing of this disclosure, and any subsequent WIL agreement, is also critical to risk management. WIL policy and the WIL agreement should require that the host supply data about their intention to own student IP prior to any WIL agreement being signed, and that the student is presented with and enters the WIL agreement before the WIL placement proceeds. Giving students time to consider any proposal to assign their IP rights minimises the risk of students claiming duress when they signed the WIL agreement.

WIL practitioners can educate students about their IP rights during course work as a prerequisite of the WIL programme, or during orientation once enrolled in the WIL programme. Formal education can equip students with an understanding of the different types of IP, types of IP ownership and the availability of legal advice on campus. For instance, students should be able to identify their own IP to minimise the risk of unwittingly assigning their background IP to the host organisation. WIL practitioners also require an IP education, particularly around the IP provisions or agreements used by their HEP, the risks associated with students assigning IP, and how to identify and assess the risk. Communities of practice in which WIL practitioners within and/or across faculties meet on a regular basis to share their experiences, is one such education method.

\section{Non-disclosure of student disability or medical condition}

The student may not disclose their disability or medical condition to the WIL discipline or the host organisation, despite questioning by the WIL discipline aimed at disclosure. Students may genuinely believe that they have the capacity and competency to complete the placement, or they fear that the HEP will reject their enrolment application if they do disclose. However, non-disclosure means that the HEP and the host organisation cannot provide reasonable accommodations for the student during their WIL placement (as 
required by law), and the HEP is denied an opportunity to match the student with a host organisation that can best meet their needs. Non-disclosure also poses reputational, financial and legal risks to HEPs. The HEP owes a duty of care to clients as well as students and staff to ensure they do not put students in situations that may cause harm to themselves or others. Non-disclosure may result in an injury to the student, a colleague or clients/patients, which may require the HEP to compensate the host under an indemnity provision in the WIL agreement and/or HEP insurance policy (financial risk). The student may be unable to complete the WIL placement, or they may fail the WIL programme (strategic risk). Overall, the HEP's relationship with the host organisation may be irrepealably damaged to the extent that the host decides not to accept any students for future placements (strategic and reputational risk).

The WIL agreement and pre-placement activities are the conventional methods of managing the legal risks associated with non-disclosure. For example, the HEP can attempt to transfer legal risk to the host organisation in its WIL agreement by providing that the HEP "has not made any representations about the student's suitability or ability to undertake the placement" and the host organisation "agrees that it has satisfied itself that the student is suitable for the placement" (University of South Australia, 2018). WIL practitioners may also ask students via questionnaires whether they have any health condition or personal circumstance which may impact their ability to meet the requirements of the WIL placement. The interview provides the WIL practitioner an opportunity to review questionnaires, conduct due diligence with academics who have taught the student, ask questions designed to gauge their capability to complete the placement, as well as highlight the importance of disclosure to assist the WIL practitioner to secure a suitable placement. Orientation or Career Development Learning (CDL) workshops, during which students participate in individual and team activities covering employability skills (e.g. teamwork, communication and etiquette), also enable the educator to identify any issues about the student's suitability for WIL. Whilst a necessary part of any risk management framework, none of these practices prevent the student from innocently or deliberately withholding disclosure.

Risk management practices need to encourage student disclosure through timely education, timely collaboration within and across HEP divisions who support students (e.g. international services, disability and equity services, student counselling), and timely 
relationship building activities with students. HEPs should foster relationships with students from the start of their degree-early intervention is at the core of managing this risk. Educators serving first year students, including subject convenors, first year advisors and programme directors, must get to know students at the earliest available opportunity so that the HEP can be trusted to manage their disability or medical issues during WIL, which normally takes place later in their degree. Relationships must also be fostered among HEP staff. For instance, first year educators can be a good source of intelligence for the WIL practitioner about students' learning difficulties, which may or may not be attributable to a disability or medical condition. This information can be a segue for the WIL practitioner to discuss strategies with the student to support them on placement, or to coordinate additional welfare checks (on-site, online and/or on-campus) during the placement.

HEPs can educate students early in their degree, through traditional study programmes or CDL modules, about: their chosen career path to trigger awareness of how their condition may impact their ability to complete tasks and responsibilities; the availability of disability and equity services and counselling support (e.g. access plans); alternative WIL models to off-campus placement that would otherwise deter students from disclosing (e.g. virtual WIL placements); and the importance of disclosing access plans to the WIL practitioner in a timely manner, so that appropriate support can be provided by the host and/or HEP. The access plan is a private arrangement between disability and equity services and the student, which identifies reasonable adjustments that should be made to the WIL programme. As such, disclosure to WIL practitioners is at the student's discretion. A continuing conversation about access plans throughout a student's degree is required to remove any perceived stigma associated with their subsequent disclosure to WIL practitioners and use in WIL programmes.

\section{Poor supervision or attitude by the host organisation}

A host organisation that exploits students or does not provide adequate supervision negatively impacts the quality of the student's learning experience and the WIL programme. Poor supervision is demonstrated by: insufficient workplace induction; failing to replace a supervisor who is absent (no supervision); requesting that the student work on a project from home and not the workplace; failing to understand the difference between work experience (student observation) and WIL (student participation); 
assigning basic tasks which are unrelated to the learning outcomes of the WIL programme; and not assigning the student with any tasks due to the workload of the host or the host being between projects. Poor supervision can negatively impact students' satisfaction with their degree, expose students to greater risk of failing the WIL programme, and may discourage them from pursuing their chosen vocation (strategic and reputation risk). Students may also complain about their WIL placement and/or appeal their grade because of poor supervision (legal and operational risk). Alternatively, students may not report such incidents or occurrences for fear of failing the WIL programme or due to cultural nuances (e.g. international students), leaving the student exposed to a hazardous workplace environment (legal risk).

HEPs can manage these risks prior to the WIL placement by employing strategic programme design, due diligence of the host, WIL agreements and education. WIL disciplines can develop alternative placement models within their programme to deliver more WIL placements and minimise the risks relating to poor supervision. For instance, the WIL discipline can offer a more structured WIL placement, using additional HEP supervision and resources, to host organisations that provide no on-site supervision (e.g. entrepreneurship programmes), or hosts that are prepared to take multiple students but do not have the resources to coordinate appropriate supervision. Dealing with one host organisation for multiple students may achieve economies of scale for HEPs to justify tailoring the WIL placement. A tailored approach may include: template learning plans which outline examples of activities a student could engage in to demonstrate the learning outcomes of the WIL programme; previous examples of projects undertaken; methods, co-ordination and frequency of host contact with the student; and more regular contact by the WIL discipline with the host and student.

WIL disciplines should conduct due diligence of the host before approving a WIL placement. An initial on-site meeting with the host, as opposed to a checklist or "tick-thebox' due diligence process, is more effective risk management and is a relationship building exercise. The WIL practitioner can engage the host by explaining the student's skills and the benefits of WIL for the host, screen the workplace for any risks, ascertain the host's motive for offering a WIL placement, identify any host supervisor training needs or resources, and reiterate the host's supervisory responsibilities and the studentcentric purpose of WIL. For example, a host organisation that requires a student's skills 
to complete tasks in an unpaid placement that would ordinarily be delegated to an employee may not have the right attitude or provide appropriate supervision to engage students in a positive student learning experience. A WIL agreement follows successful due diligence. The learning objectives of the WIL placement and the obligations of the student and host must be clearly articulated, including host supervision, and where relevant required, a warranty about the qualifications and experience of the supervisor.

HEPs can manage the risk of poor supervision during placement by managing host and student relationships. The HEP requires ongoing engagement with the host during the WIL placement to ensure that the host is complying with their supervisory responsibilities. As with pre-placement due diligence, the frequency and length of engagement with the host is dependent on the resources to undertake these activities (operational risk) and any professional requirements which mandate site visits (e.g. Social Work). Nevertheless, a WIL practitioner should conduct at least one meeting (preferably on-site) with the student and host supervisor together, unless otherwise requested by either party. This meeting can be a mid-placement review, during which the student receives feedback on their progress, and any issues with or adjustments to the placement can be discussed to ensure the placement outcomes are achieved.

The host supervisor also needs timely and open access to WIL practitioners to discuss any placement issues. This relationship will be tested if poor supervision or attitude is identified. The WIL discipline does not want to permanently damage the host relationship, thus denying students future placements (strategic risk), but failing to address poor host behaviour exposes the student to an exploitative environment and undermines their learning experience. A conversation may be required to re-educate the host supervisor about the purpose of WIL, and to suggest and agree on methods to resolve any issues. Host supervisors can be supported with training (on-site or on-campus) and resources (handbooks and information sheets) about WIL and their supervisory role and responsibilities, including how to manage students from diverse and challenging backgrounds. For instance, one university has established a site within its learning management system (LMS) for host supervisors to access education resources, and a forum to share their experiences, ask questions and communicate with one another.

The WIL discipline can manage the student relationship by employing a broad range of touchpoints during their placement: a central WIL e-mail address and phone number, 
meetings, online tools, assessment and classes. A weekly drop-in session enables students to ask questions, and to seek clarification and re-assurance as to what they are observing or experiencing on placement. An e-mail shortly after starting the placement can check in to see how the student is settling in, followed by another email at the mid-point of their placement to assess their progress against the WIL placement outcomes. A reflective online journal is a form of assessment and a method of reviewing host supervision. Students submit regular journal entries in response to prompting questions during placement, which are read by the WIL discipline, and any perceived issues, including poor supervision or attitude by the host, are followed up with the student and/or host organisation. For instance, a student at one university felt they were unsupported and not allocated meaningful work. This triggered conversations between the WIL discipline and host organisation about the purpose of WIL, and with the student who had the opportunity to voice their concerns to the host. In exceptional circumstances, good relationship management may involve the WIL discipline removing the student from the placement and finding an alternative placement.

\section{A host organisation does not offer a WIL placement}

The HEP's failure to attract and retain host organisations affects the supply of WIL placements to students. No host organisation means no WIL placement, which impacts the HEP's goals in relation to the delivery of WIL programmes (strategic risk). If the WIL discipline cannot place the student, students may complete course work in other disciplines or move to another HEP that can source a WIL placement (financial and strategic risk). Further, students may be unable to graduate according to their intended or mandated time frame (reputation risk), with serious implications for international students who may have to extend their visa to complete their degree. WIL disciplines must also divert their limited resources to sourcing and cultivating more host relationships to cover the loss of host organisations (operational risk).

The potential causes of this risk are many and varied. A WIL practitioner, who has fostered the host relationship, may leave the HEP without the WIL discipline having in place a succession strategy to maintain the relationship. HEPs may also place operational roadblocks before hosts including: complex and lengthy WIL agreements, inflexibility with the timing of WIL placements, and poor communication between the host organisation and WIL discipline. Hosts may not offer a placement based on the perceived 
quality of the proposed student, or their experiences with previous students on placement. Hosts may also perceive that they do not have the time, resources or skills to support WIL placements.

HEPs can manage this risk by attracting, retaining, and in exceptional circumstances, terminating host organisations when the HEP cannot assure the quality of the WIL placement. HEPs can attract host organisations, and thereby increase the supply of WIL placements, by pursuing alternative sources and types of WIL placements, by facilitating placement starts throughout the year (365-day model), as well as building value-added relationships with hosts. Alumni, particularly graduates of the WIL programme, are an excellent source of cultivating new WIL placements. A strong alumni programme, which is characterised by professional activities and communication strategies that engage graduates, improves the prospects of securing support for placements. Alternatives to the traditional off-campus WIL placement sourced by the WIL discipline include: virtual placements; on-campus placements in which the WIL discipline is responsible for providing a workspace for students to complete a project for a host organisation; and selfsourced placements, whereby the student approaches a host for a placement. The WIL discipline provides guidance and the parameters for approving the self-sourced placement in terms of supervision, proposed tasks to meet the learning outcomes, and a WIL agreement.

HEPs can also build value-added relationships with host organisations, that is offer benefits to the host beyond the WIL placement. For example, HEPs can create innovative industry partnerships by connecting actual and prospective hosts to academic expertise in research and consulting, delivering professional development training for hosts and providing hosts with access to other HEP resources (e.g. online tools, library materials). HEPs can also engage hosts in teaching and learning activities such as site visits, case studies, mock interviews and other experiential learning opportunities that benefit from industry feedback. A host organisation may not have a WIL placement at one point in time. However, using innovative forms of engagement may keep the HEP in mind for future WIL placements.

Attracting and retaining hosts also requires effective WIL systems (IT, communication, HR and Legal) to manage the relationship. A CRM captures data about industry engagement across the HEP, particularly communications with the host, processes for 
approaching a prospective host and managing the relationship, and the HEP representatives who are the primary host contact points. This information sharing on the CRM can also manage operational risk associated with staff turnover. WIL practitioners can access the CRM to identify prospective hosts and use the host contact points as a source of intelligence and a lead into the host organisation, as opposed to 'cold-calling' the host. Effective communication by the HEP includes on-site visits before and during WIL placements to potential and current hosts, listening and responding to host feedback, and providing the host with an opportunity to evaluate their relationship with the HEP and the WIL experience. In fact, many HEPs employ relationship management specialists, known as Industry Engagement Officers or Managers, to be the primary host contact. Their objectives are to source and then support hosts during the WIL programme. Finally, WIL agreements should be tailored to the profile of the host. For instance, a small business may appreciate a simple WIL agreement template (2-3 pages) prepared by the HEP which is unlikely to require independent legal advice, whereas a multi-national entity may have its own sophisticated risk management systems and legal team to prepare a lengthier more complex document for the HEP to consider.

\section{WIL practitioners have insufficient legal literacy}

HEPs are exposed to legal risk if WIL practitioners do not understand the legal rights and obligations of stakeholders under HEP policy, the WIL agreement or when designing the WIL programme. This is referred to as their 'legal literacy' (Cameron, 2016). This risk is demonstrated by WIL practitioners: being unable to identify risks in WIL; breaching WIL policy or the WIL agreement through their general conduct or decision-making; and poor WIL programme design, such as WIL placements that do not provide students with opportunities to meet the learning outcomes.

The employment contract can be a catalyst for improving the legal literacy of WIL practitioners by making risk management, legal knowledge and a thorough understanding of WIL documentation part of the WIL practitioner's roles and responsibilities. Once employed, WIL practitioners can receive training about their risk management responsibilities during the WIL programme, legal issues in WIL, conflict resolution and negotiation skills, host relationship management, the purposes of WIL, and WIL documents. WIL practitioners can also educate colleagues by sharing their knowledge, experience and best practice in WIL. HEPs can support education by resourcing WIL 
communities of practice comprised of representatives across WIL disciplines and HEP divisions (disability and equity services, legal, risk and insurance). This cross-disciplinary collaboration can take place on-line (e.g. an LMS page) and in-person through regular meetings involving external presentations and general discussion on WIL topics.

HEP strategies which centralise WIL functions and enable timely access to legal services may also improve the legal literacy of WIL practitioners. For instance, one institution recently formed a team of specialist WIL lecturers and industry engagement personnel who deliver services across multiple campuses. Decision-making related to WIL, such as WIL procedures and programme design, is a collaborative process to ensure 'buy in' and further understanding of the WIL programme. This central WIL team educate each other about their field of expertise-industry engagement personnel gain knowledge about programme design from WIL lecturers, and WIL lecturers learn about the day-to-day operation of the placement from industry engagement personnel. Another university has central WIL support teams who provide timely advice, education and resources across WIL disciplines, dedicated HEP lawyers with WIL expertise, and contract staff who manage WIL agreements. In one example, a student complained that they could not start their placement because the host organisation refused to sign a WIL agreement in which the student retained their IP rights. The lawyer advised the WIL practitioner that the student could elect to assign their IP to the host organisation, which was assessed as low risk because of the placement type, and provided information for the WIL practitioner to explain the IP assignment clause to the student.

\section{Discussion and conclusions}

It is important for HEPs to understand that the strategic expansion of WIL opportunities to students is likely to be accompanied by greater risks to WIL stakeholders (Cooper et al., 2010). WIL practitioners described a series of risk management practices in response to five significant risks in WIL programmes, which can be applied by WIL stakeholders to evaluate and improve their institution's risk management framework, and to improve their legal literacy in relation to WIL. For example, the findings may prompt consideration about adopting one or more risk management practices, or may validate existing practices as part of a benchmarking exercise by the HEP. 
Four themes also emerged from the study-balance, collaboration, relationship management, and resources - which have been conceptualised as characteristics of risk management in the sections which follow. They can act as guiding principles for WIL stakeholders in risk management. The article concludes by evaluating and advocating cross-institutional collaboration, particularly the capacity of collaborative research to improve WIL practice.

\section{Characteristics of risk management}

\section{Risk management is a balance}

Risk management is a balance between the opportunities and hazards (or risks) associated with WIL, as well as a balance between risks. WIL practitioners raised two scenarios which raised issues of balance. In the first scenario, a more flexible delivery of WIL programmes (365-day model), or centralised WIL teams with dedicated engagement personnel, may increase the number of WIL placements and improve host relationships (opportunity). However, both risk management practices impose hiring costs that the institution may not be willing to provide (financial risk) or place additional burden on existing WIL practitioners (operational risk). In the second scenario, a WIL practitioner who removes a student from the workplace because of poor host supervision to minimise legal and reputation risk, may risk irreparable damage to the host relationship (strategic risk). On the flipside, a focus on retaining the host relationship may see the student remain in a workplace that is inherently risky. In both scenarios, a risk management practice causes other risks that need to be managed by the HEP. A co-ordinated risk management strategy, incorporating multiple practices, may be required to achieve an appropriate balance between opportunity and hazard (scenario 1) and between risks (scenario 2).

\section{Risk management is collaborative}

Risk management involves collaboration within and across WIL disciplines and HEP divisions. A closely related concept is shared responsibility, namely that risk management is the responsibility of every person associated with WIL. As one WIL practitioner noted, "risk management is everyone's responsibility. Too often it is seen as the domain of specific functions". Centralisation, whether that be a WIL team and/or a CRM, may facilitate collaboration, as can formal WIL communities of practice to improve the legal literacy of WIL practitioners. 


\section{Risk management is relationship management}

HEPs that effectively manage their relationships with students and host organisations by clearly articulating stakeholder rights and obligations, as well as providing timely communication and education, can minimise risk in WIL. A theme underpinning the risks described in this study is the negative impact on host and student relationships should the risk manifest. For example, HEPs need to engage in timely relationship management with students to encourage disclosure of their disability, as non-disclosure may cause the host to decline future WIL placement requests (strategic and reputation risk).

\section{Risk management is resourced}

HEPs must be prepared to properly resource risk management through money, people, time and technology. A HEP's failure to assure the quality of WIL programmes because of limited resources is no excuse. Risk management resources described in the study include a CRM, relationship management specialists, WIL agreement templates, WIL education resources, communities of practice, and education programmes delivered to hosts and students.

\section{Cross-institutional collaboration}

As part of the study design, the authors reflected on the collaborative process. The study design guided WIL researchers, with varying levels of research experience, in making a meaningful contribution. Google Docs was not only a method of data collection, but also facilitated accountability, dialogue and more robust responses (or 'richer data') because authors had unfettered access to their colleagues' ongoing contributions. Nevertheless, the collaborative process was more time-consuming than originally anticipated. Research is an 'add-on' responsibility for WIL practitioners who do not have the time or resources to immerse themselves in research amid their substantial WIL commitments. Time and workload issues have previously been identified as constraints on cross-institutional collaboration in WIL (Hay, 2011). In retrospect, the lead author could have also expedited the collaborative process by setting in-person or online meetings during the collaboration.

Despite its limitations, the collaborative research is already having a positive impact on institutional risk management. HEPs associated with the authors are already applying the research findings. Practical outcomes of the research have included improved legal 
literacy of WIL practitioners in identifying risks and applying risk management practices that were not originally contemplated by their HEP, the inclusion of risk management education in CDL modules, and the development of a WIL risk template which documents: the risk, assessment of the risk, and the actions to manage the risk. Overall, a key message from this study should be that collaborative research involving WIL practitioners can improve WIL practice. As such, HEPs and WIL associations should consider implementing and reviewing schemes aimed at growing WIL communities of research.

\section{References}

Ackley, S., Adams, M., Crickette, G., Eick, C., Finch, L., Freeman, R., Bonney, H., Langsdale, G., Lark, C., Shew Holland, E. and Unks, R. (2007), "ERM in higher education”, University Risk Management and Insurance Association, Wheaton, IL.

Berg-Weger, M., Rochman, E., Rosenthal, P., Sporleder, B. and Birkenmaier, J. (2007), "A multi-program collaboration in field education", Social Work Education, Vol. 26 No. 1, pp. 20-34.

Bravenboer, D., and Lester, S. (2016), “Towards an integrated approach to the recognition of professional competence and academic learning", Education + Training, Vol. 58 No. 4, pp. 409-421.

Cameron, C. (2016), "Work integrated learning: A study of risk management by university lawyers", unpublished Ph.D. dissertation, Griffith University, Australia.

Cameron, C., Dodds, C. and Maclean, C. (2019), "Ethical risks in work-integrated learning: A study of Canadian practitioners", International Journal of WorkIntegrated Learning, Vol. 20 No. 1, pp. 83-95.

Cassidy, D., Goldstein, L., Johnson, S., Mattie, J. and Morley Jr., J., (2001), "Developing a strategy to manage enterprisewide risk in higher education" available at: National Association of College and University Business Officers, 
available at: https://www.ucop.edu/enterprise-risk-

management/_files/nacubo_rm.pdf(accessed 12 May 2019).

Cooper, L., Orrell, J. and Bowden, M. (2010), Work Integrated Learning: A Guide to Effective Practice, Taylor \& Francis, London.

Copyright Act 1968 (Cth)

Freudenberg, B., Brimble, M. and Cameron, C. (2010), "Where there is a WIL there is a way", Higher Education Research \& Development, Vol. 29 No. 5, pp. 575-588.

Gonsalvez, C. J., Bushnell, J., Blackman, R., Deane, F., Bliokas, V., Nicholson-Perry, K., Shires, A., Nasstasia, Y., Allen, C. and Knight, R. (2013), “Assessment of psychology competencies in field placements: Standardized vignettes reduce rater bias", Training and Education in Professional Psychology, Vol. 7 No. 2, pp. 99-111.

Hay, K. (2011), "Can collaboration and competition co-exist? Building a crossinstitutional community of practice", Asia-Pacific Journal of Cooperative Education, Vol. 12 No. 1, pp. 31-38.

Higher Education and Research Act 2017 (UK)

Higher Education Standards Framework (Threshold Standards) 2015 (Cth)

Merriam, S. M. (2009), Qualitative Research: A Guide to Design and Implementation, Jossey-Bass, San Francisco, CA.

National Centre for Vocational Education Research (2019), "Higher Apprenticeships in Australia: What are we talking about?", available at: https://www.ncver.edu.au/research-and-statistics/publications/allpublications/higher-apprenticeships-what-are-we-talking-about (accessed 3 September 2019).

Patrick, C-J., Peach, D., Pocknee, C., Webb, F., Fletcher, M. and Pretto, G. (2008), "The WIL [Work integrated learning] report: A national scoping study", available at: https://eprints.qut.edu.au/44065/ (accessed 12 May 2019). 
Rowe, P.M. (2015), Researchers' reflections on what is missing from work-integrated learning research, Asia-Pacific Journal of Cooperative Education, Vol. 16 No. 12, pp. 101-107.

Saldana, J. (2013), The Coding Manual for Qualitative Researchers, Sage, Thousand Oaks, CA.

Tertiary Education Quality and Standards Agency. (2017), “Guidance note: work integrated learning", available at: https://www.teqsa.gov.au/latestnews/publications/guidance-note-work-integrated-learning (accessed 12 May 2019).

Trinidad, S., Sharplin, E., Ledger, S. and Broadley, T. (2014), Connecting for innovation: Four universities collaboratively preparing pre-service teachers to teach in rural and remote Western Australia, Journal of Research in Rural Education, Vol. 29 No. 2, pp. 1-13.

University of South Australia, Course-Assessed Placement Agreement (on file with author).

Zegwaard, K. E. (2015), Building an excellent foundation for research: Challenges and current research needs, Asia-Pacific Journal of Cooperative Education, Vol. 16 No. 2, pp. 89-99. 